\title{
Histone deacetylase modulators provided by Mother Nature
}

\author{
Carole Seidel $\cdot$ Michael Schnekenburger • \\ Mario Dicato $\cdot$ Marc Diederich
}

Received: 12 October 2011 / Accepted: 24 January 2012/Published online: 12 February 2012

(C) Springer-Verlag 2012

\begin{abstract}
Protein acetylation status results from a balance between histone acetyltransferase and histone deacetylase (HDAC) activities. Alteration of this balance leads to a disruption of cellular integrity and participates in the development of numerous diseases, including cancer. Therefore, modulation of these activities appears to be a promising approach for anticancer therapy. Histone deacetylase inhibitors (HDACi) are epigenetically active drugs that induce the hyperacetylation of lysine residues within histone and non-histone proteins, thus affecting gene expression and cellular processes such as proteinprotein interactions, protein stability, DNA binding and protein sub-cellular localization. Therefore, HDACi are promising anti-tumor agents as they may affect the cell cycle, inhibit proliferation, stimulate differentiation and induce apoptotic cell death. Over the last 30 years, numerous synthetic and natural products, including a broad range of dietary compounds, have been identified as HDACi. This review focuses on molecules from natural origins modulating HDAC activities and presenting promising anticancer activities.
\end{abstract}

Keywords Protein acetylation - HDAC - HDAC modulators $\cdot$ Natural compounds $\cdot$ Cancer

C. Seidel · M. Schnekenburger · M. Dicato · M. Diederich $(\square)$ Laboratoire de Biologie Moléculaire et Cellulaire du Cancer, Fondation de Recherche Cancer et Sang, Hôpital Kirchberg, 9 Rue Edward Steichen, 2540 Luxembourg, Luxembourg e-mail: marc.diederich@lbmcc.lu

\section{Introduction}

Post-translational modifications of proteins play a crucial role in the modulation of their function by altering proteinprotein and protein-nucleic acid interactions as well as their subcellular localization and activity. Specialized enzymes catalyze the addition and elimination of these modifications at specific sites. For example, kinases and phosphatases are responsible for the addition and removal of phosphate groups, respectively, on factors regulating signaling pathways or the cell cycle, whereas ubiquitin ligases are mainly involved in protein targeting to the proteasome. Histone acetyl transferases (HATs) and histone deacetylases (HDACs) regulate the balance of lysine acetylation on histones and non-histone proteins (Fig. 1; Spange et al. 2009). Lysine acetylation is deeply implicated in the control of highly regulated biological functions. Thus, alteration of the acetylation status is involved in the development of many diseases, including tumorigenesis. Therefore, the control of the acetylation status by modulating HDAC activities is a promising approach to anticancer therapy. Over the last 30 years, numerous synthetic and natural products, including a broad range of dietary compounds, have been identified as HDAC modulators. This review focuses on promising modulators of HDAC activity from natural sources and discusses their potential for anticancer therapy.

\section{The HDAC family: classification, roles and substrates}

\section{HDAC isoforms}

HDACs are ubiquitous enzymes, initially identified as being responsible for the deacetylation of histones (Fig. 1), 
Fig. 1 Acetylation/ deacetylation of lysine residues. The reaction of acetylation on the $\varepsilon$-nitrogen of lysine residues is catalyzed by enzymes within the histone acetyl transferase (HAT) family, using acetylcoenzyme A (acetyl-CoA) as donor of acetyl moiety. This is a reversible reaction catalyzed by enzymes within the histone deacetylase (HDAC) family

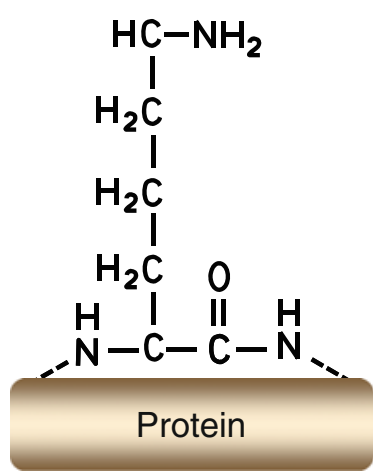

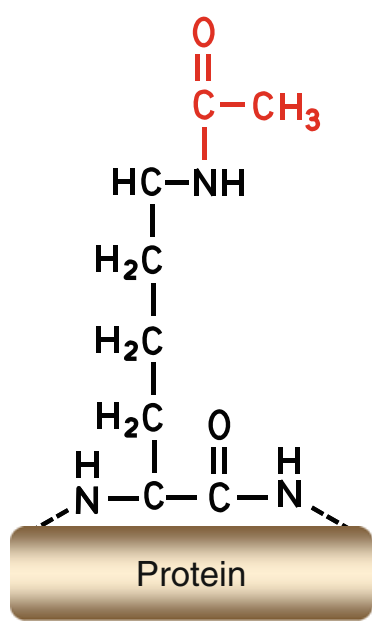

Table 1 Presentation of the different HDAC isoforms

\begin{tabular}{|c|c|c|c|}
\hline \multicolumn{2}{|c|}{ HDAC } & \multirow[t]{2}{*}{ Cellular localization } & \multirow[t]{2}{*}{ Substrates } \\
\hline Class & Member & & \\
\hline \multirow[t]{4}{*}{ I } & HDAC1 & Nucleus & Histones, DNMT1, SHP, ATM, MEF2, MyoD, p53, NF- $\kappa$ B, AR, BRCA1, MECP2, pRb \\
\hline & HDAC2 & Nucleus & Histones, NF- $\kappa \mathrm{B}$, GATA2, BRCA1, pRb, MECP \\
\hline & HDAC3 & Nucleus & Histones, HDAC4, 5, 7 et 9, SHP, GATA1, NF- $\kappa$ B, pRb \\
\hline & HDAC8 & Mainly in the nucleus & HSP70 \\
\hline \multirow[t]{4}{*}{ IIa } & HDAC4 & Nucleocytoplasmic traffic & Histones, HDAC3, MEF2, CaM, 14-3-3 \\
\hline & HDAC5 & Nucleocytoplasmic traffic & Histones, HDAC3, MEF2, CaM, 14-3-3 \\
\hline & HDAC7 & Nucleocytoplasmic traffic & Histones, HDAC3, MEF2, CaM, 14-3-3, HIF- $1 \alpha$ \\
\hline & HDAC9 & Nucleus & Histones, HDAC3, MEF2, CaM, 14-3-3 \\
\hline \multirow[t]{2}{*}{ IIb } & HDAC6 & Mainly in the cytoplasm & HDAC11, SHP, PP1, $\alpha$-tubulin, HSP90 \\
\hline & HDAC10 & Nucleus and cytoplasm & LcoR, PP1 \\
\hline \multirow[t]{7}{*}{ III } & SIRT1 & Mainly in the nucleus & FOXO, p53, p300, NF- $\kappa \mathrm{B}$, histones \\
\hline & SIRT2 & Nucleus and cytoplasm & Histone $\mathrm{H} 4, \alpha$-tubulin, PPAR- $\gamma, \mathrm{FOXO}, \mathrm{p} 53, \mathrm{p} 300$ \\
\hline & SIRT $^{\mathrm{b}}$ & Mitochondria & PGC- $1 \alpha$, FOXO, p53, Ku70, Acetyl-CoA synthetase 2, complex I \\
\hline & SIRT $4^{\mathrm{a}}$ & Mitochondria & Glutamate dehydrogenase \\
\hline & SIRT5 & Mitochondria & Cytochrome c, carbamoyl phosphate synthetase 1 \\
\hline & SIRT6 $^{\mathrm{b}}$ & Nucleus & Histone $\mathrm{H} 3, \mathrm{TNF}-\alpha$ \\
\hline & SIRT7 & Mainly in the nucleus & p53, RNA polymerase I \\
\hline IV & HDAC11 & Nucleus & HDAC6 \\
\hline
\end{tabular}

$A R$ androgen receptor, $A T M$ ataxia-telangiectasia-mutated, BRCA breast cancer, CaM calmodulin, CoA co-enzyme A, DNMT DNA methyltransferase, FOXO forkhead box O, GATA GATA binding protein, HDAC histone deacetylase, HIF hypoxia-inducible factor, $H S P$ heat shock protein, $L c o R$ ligand-dependent receptor co-repressor, $M E C P$ methyl-CpG-binding domain protein, $M E F$ myocyte enhancer factor, $N F-\kappa B$ nuclear transcription factor-kappa $\mathrm{B}, P G C$ peroxisome proliferator-activated receptor gamma coactivator, $P P 1$ protein phosphatase, $P P A R$ peroxisome proliferator-activated receptor, $p R b$ retinoblastoma protein, SHP Src homology region 2-domain-containing phosphatase, SIRT sirtuin, TNF tumor necrosis factor

${ }^{\text {a }}$ SIRT4 is an ADP-ribosyltransferase and lacks deacetylase activity

b SIRT3 and 6 possess, in addition to their deacetylase activity, the ADP-ribosyltransferase activity (adapted from Folmer et al. 2010)

and are capable of targeting many non-histone proteins as substrates (Table 1). The 18 HDACs identified in mammals are divided into four classes according to both their sequence identity and catalytic activity.
Class I includes HDAC1, 2, 3 and 8, which are located mainly in the nucleus. HDAC3 forms an exception to this class because it possesses, in addition to the nuclear localization signal (NLS) present in this HDAC class, a 
nuclear export signal (NES), which suggests a possible cytoplasmic localization. The activity of these enzymes is modulated when they interact with chromatin proteins such as $\operatorname{Sin} 3$ (Switch intensive 3), NuRDs (nucleosome remodeling and deacetylating) and Co-REST (Co-repressor of REST; Zhang et al. 1999).

Class II is divided into two subclasses: subclass IIa includes HDAC4, 5, 7 and 9 and subclass IIb consists of HDAC6 and 10. HDAC9 is localized exclusively to the nucleus, whereas HDAC4, 5 and 7 contain an NLS and NES. These three enzymes are localized to both the nucleus and the cytoplasm. The catalytic activity of class IIa HDACs is very low and is hardly detectable in vitro (Fischle et al. 2002). In addition, it has been shown in cellulo that these enzymes are often complexed with other HDACs, suggesting a role different from that of a deacetylase. For example, HDAC4 allows the recruitment of the SMRT/N-CoR-HDAC3 complex to specific promoters, leading to transcriptional repression of targeted genes (Fischle et al. 2002). HDAC6 is mainly localized to the cytoplasm, where it is involved in the deacetylation of $\alpha$-tubulin and consequently, regulation of microtubuledependent cell motility. Moreover, this enzyme is able to target the chaperon protein HSP90, which stabilizes client proteins (Bali et al. 2005). This HDAC has two catalytic domains arranged in tandem and one functional HUB (HDAC6-, USP3- and Brap2-related zinc finger motif) domain absent in other HDACs. This domain is located in the C-terminal region and acts as a signal for ubiquitination of HDAC6, leading to its degradation. HDAC10 possesses, like other class IIa HDACs, both NLS and NES domains. Although the catalytic domain is located in the N-terminal region, a second putative domain is located in the C-terminal region. In addition, two putative retinoblastoma $(\mathrm{Rb})$ protein-binding domains are present, which could explain the involvement of this enzyme in regulating the cell cycle. HDAC10 interacts with six other HDACs (HDAC1, 2, 3, 4, 5 and 7), suggesting a recruiting role rather than acting as a deacetylase (Tong et al. 2002). Class III, also called sirtuins for their analogy to the protein SIR2 (Silent Information Regulator 2) in yeast, contains seven members, SIRT1 to 7. SIRT1, 6 and 7 are localized to the nucleus. SIRT1 positively regulates transcription factors such as the nuclear factor kappa-B (NF- $\kappa \mathrm{B})$, p53 and forkhead box (FOX) proteins and plays a role in chromatin condensation (i.e., histone deacetylation). SIRT6 and 7 are involved in DNA repair and ribosomal RNA transcription, respectively. SIRT2 is mainly localized to the cytoplasm and affects $\alpha$-tubulin acetylation status. SIRT3, 4 and 5 are mitochondrial proteins. SIRT3 positively regulates the activity of the acetyl-Coenzyme A synthetase 2, leading to the production of acetyl-coenzyme A (Hallows et al. 2006; Schwer et al. 2006), and deacetylates complex I of the respiratory chain involved in ATP production (Ahn et al. 2008). Thus, SIRT3 regulates energetic cell homeostasis. SIRT4 lacks deacetylase activity; however, it has an ADPribosylase activity. This ribosylation inactivates glutamate dehydrogenase, which in turn inhibits insulin secretion in pancreatic $\beta$-cells (Argmann and Auwerx 2006). Lastly, SIRT5 deacetylates and thus activates carbamoyl phosphate synthetase 1 , which promotes ammonia detoxification (Nakagawa and Guarente 2009; Nakagawa et al. 2009).

Class IV comprises only HDAC11, which is localized in the nucleus and has a catalytic domain in the N-terminal region. This enzyme is structurally related to HDAC 3 and 8 of class I, but also has similarities with class II; for these reasons, this new class of enzyme was created (Gao et al. 2002).

The reaction of deacetylation

Classes I, II and IV possess a zinc-dependent mechanism of action. Their catalytic domain in the $\mathrm{N}$ - or C-terminal region forms a tubular pocket with the zinc ion at the bottom. This ion is stabilized by two aspartate and one histidine residue and forms electrostatic bonds with a catalytic water molecule and the oxygen of the acetyl functional moiety of the substrate. Due to an electron transfer between the aspartate and histidine residues, the catalytic water molecule is activated, allowing a nucleophilic attack on the carbon of the acetyl moiety. This reaction leads to an oxyanion tetrahedral intermediate stabilized by a tyrosine residue in the catalytic site. Then, the nitrogen of the substrate lysine involved in the bond with the acetate accepts a proton from an aspartate-histidine relay. Hence, the carbon-nitrogen bond is broken and both the deacetylated substrate and the acetate are released (Finnin et al. 1999; Hodawadekar and Marmorstein 2007).

Class III relies on a nicotinamide adenine dinucleotide $\left(\mathrm{NAD}^{+}\right)$-dependent mechanism. However, based on crystallographic studies, two alternative mechanisms have been suggested. In the first model, the nicotinamide group is hydrolyzed, allowing the nucleophilic attack of the acetate's oxygen to the $1^{\prime}$ carbon of the remaining ribose. In the second model, the nucleophilic attack of the acetate's oxygen at the $1^{\prime}$ carbon of the $\mathrm{NAD}^{+}$-ribose leads to the release of the nicotinamide. In both cases, once the acetyl group is bonded to the $1^{\prime}$ carbon of the ribose, there is a proton transfer facilitated by a histidine in the catalytic site, which renders the $2^{\prime}$ oxygen nucleophilic. This oxygen will then attack the carbon of the acetate, and this reaction will result in the formation of a cyclic intermediate. The nitrogen of the substrate's lysine then accepts a proton from a histidine. This transfer then breaks the connection between the acetate and the lysine. Reaction products are 
nicotinamide, deacetylated protein and 2-O'-acetyl-ADPribose. The latter will be recycled with the addition of nicotinamide and removal of the acetyl group (Hodawadekar and Marmorstein 2007; Hoff et al. 2006).

\section{Cellular targets of acetylation}

HDAC activity is involved, due to the large range of substrates, in many cellular processes (Table 1). Indeed, gene expression is modulated by the acetylation status of histones and transcription factors. Acetylation of histone lysine residues modulates histone-DNA and histone-protein interactions as well as chromatin remodeling. Thus, hyperacetylation of histones is associated with a relaxed state of chromatin and active gene expression (Minucci and Pelicci 2006). Moreover, acetylation of transcription factors affects their cellular localization. Indeed, NF- $\kappa \mathrm{B}$, as well as STAT1 (signal transducer and activator of transcription 1) and STAT3, is translocated into the nucleus following acetylation of specific lysine residues, where they activate the transcription of target genes. Interestingly, the transactivation function of other transcription factors, such as p53 and FOXO proteins, is also positively regulated by acetylation. In addition, the activity of the $\mathrm{Rb}$ protein is modulated by the presence of acetyl groups blocking its cyclin E-CDK (cyclin-dependent kinase) 2-dependent phosphorylation. This acetylation-dependent hypophosphorylation leads to cell cycle arrest. Moreover, the acetylation of factors involved in maturation, stability and translation of messenger RNA can have an impact on their function. Indeed, the acetylation of hnRPA1 (heterogeneous nuclear ribonucleoprotein A1) and PAP (poly[A]-polymerase) modifies the interaction between these proteins with pre-mRNA. Protein stability can also be affected by acetylation of proteins destined to the proteasome. Indeed, the acetylation of p53, p73, Smad7 (mothers against decapentaplegic homolog 7) and c-myc prevents their ubiquitination and thus their degradation. In contrast, acetylation of HIF- $1 \alpha$ (hypoxia-inducible factor- $1 \alpha$ ) facilitates its interaction with ubiquitin-ligase E3 and transit to the proteasome. Interestingly, cell mobility is dependent on $\alpha$-tubulin and cortactin acetylation status. Indeed, HDAC6and SIRT2-mediated deacetylation of $\alpha$-tubulin promotes microtubule depolymerization and therefore increases microtubule dynamics and cell mobility (Hubbert et al. 2002). In addition, deacetylated cortactin promotes cell motility by interacting with F-actin, leading to actin polymerization (Aldana-Masangkay and Sakamoto 2011).

Finally, the microtubule network is necessary for an active clearance of cytotoxic misfolded protein through the aggresome pathway (Johnston et al. 1998). This alternative pathway of protein degradation via aggresome organelles protects cells against an overloading of the ubiquitin proteasome-system (UPS) due to an accumulation of misfolded proteins in cellular stress conditions. In this system, HDAC6 that possesses a ZnF-UBP (zinc-finger ubiquitin binding) domain binds polyubiquitinated misfolded proteins and delivers them to p150(Glued), a component of dynein/dynactin microtubule motor complex. Misfolded protein are then transported to the MTOC (microtubule organizing center), where aggresomes are formed leading to the activation of the autophagic clearance activation that allow degradation of misfolded proteins in a proteasomeindependent manner (Aldana-Masangkay and Sakamoto 2011; Lee et al. 2010).

\section{HDAC inhibitors in cancer therapy}

Epigenetic alterations and cancer

Carcinogenesis is not exclusively due to mutations of the nucleotide sequence but also involves epigenetic alterations. Thus, according to the major role played by protein acetylation in gene expression, a disruption in the balance between HAT and HDAC activities may contribute to the transformation of a normal cell to a cancerous cell (Fig. 2). Indeed, aberrant hypoacetylation of histones and non-histone proteins, caused by a decrease in HAT activities, aberrant HDAC recruitment to the promoter regions of certain genes (e.g., tumor suppressor genes [TSGs]) and/or increase in HDAC expression leading to excessive gene silencing, is frequently observed in many forms of cancer. More precisely, a decrease in HAT activities could be due to either mutations of HAT isoforms, such as p300, or chromosomal translocations. The latter leads to the formation of fusion proteins such as MLL-CBP, MLL-p300, MOZ-CBP, MOZ-p300 or MOZTIF2 involved in aberrant gene expression. For example, in a normal state, MOZ controls RUNX1 expression, which is involved in cell differentiation, whereas the fusion protein MOZ-CBP induces the repression of this protein, thus promoting carcinogenesis (Bug and Ottmann 2010; Florean et al. 2011). Moreover, chromatin modifications induced by alterations in histone acetylation status of specific genes could be due to aberrant HDAC recruitment triggered by leukemia-associated fusion proteins, such as PLZF-RAR (promyelocytic leukemia zinc finger-retinoic acid receptor- $\alpha$ ) or PML-RAR (promyelocytic leukemia-retinoic acid receptor- $\alpha$ ) in promyelocytic leukemia. Indeed, the RAR is able to bind DNA with HDAC-containing complexes and repress transcription of target genes in the absence of a ligand. The presence of retinoic acid disrupts these inhibitory complexes to the benefit of transcriptional activator complexes, which contain HAT. The fusion-proteins PLZF-RAR and PML- 
RAR block this dissociation and recruit other enzymes involved in chromatin structure modifications, promoting a drastic inhibition of transcription (Florean et al. 2011; Minucci and Pelicci 2006). This mechanism is responsible for aberrant recruitment of HDACs to specific promoters involved in differentiation and impairs p53 functions, which play an important role in leukemogenesis. In addition to their involvement in the early stages of tumorigenesis and cancer development, aberrant cooperation between HATs and HDACs can influence tumor invasion and metastasis properties (Tai et al. 2007). Moreover, in some cancers, HDAC isoforms are either overexpressed, as with HDAC1, 2, 6, 8 and SIRT1, or underexpressed, as with HDAC4, 5 and SIRT4 (Bradbury et al. 2005). Finally, sirtuins are known to induce angiogenesis, which is critical for tumor growth and metastasis (Liu et al. 2009; Potente et al. 2007). In addition to histone acetylation, other histone modifications such as methylation are involved in chromatin structure and act together with DNA methylation on TSG silencing (Fig. 2; Florean et al. 2011; Hassan et al. 2007; Jones et al. 1998; Wade et al. 1999). Altogether, these mechanisms are implicated in apoptosis resistance, differentiation arrest, cell cycle perturbations leading to aberrant proliferation associated with tumorigenesis and tumor aggressiveness, including invasiveness and metastasis.

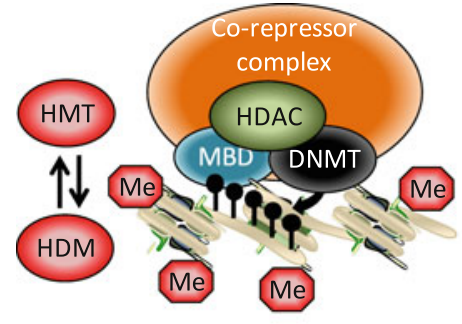

TSG in cancer cells

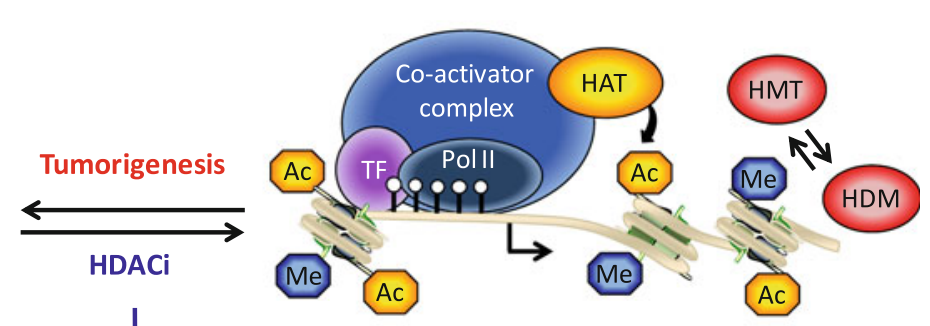

TSG in normal cells

> Control of protein stability:

- Induction of proteosomal degradation (e.g. HIF-1 $\alpha$ )

- Inhibition of proteosomal degradation (e.g. p53, p73, Smad7, c-myc)

$>$ Cell cycle arrest:

- Induction of cell cycle inhibitors (e.g. CDKN1A)

- Inhibition of cell cycle progression-related genes (cyclins, CDKs)

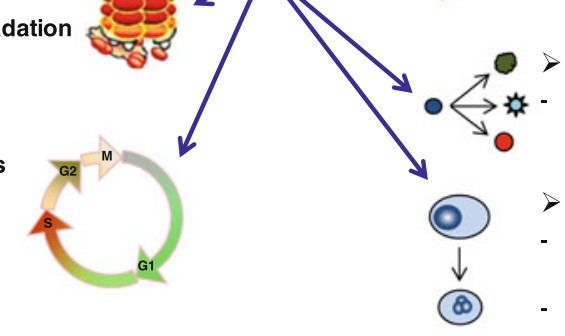

Inhibition of telomerase activity: Inhibition of hTERT mRNA transcription

\section{Induction of differentiation:}

Activation of differentiation-related genes (e.g. RUNX1, cytokeratin 7)

Induction of apoptosis:

Inactivation of anti-apoptotic proteins (e.g. Bcl-2, survivin)

Induction of pro-apoptotic proteins (e.g. Bax, Bak)

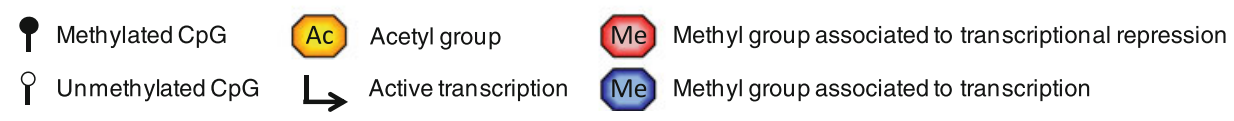

Fig. 2 Effects of HDAC inhibitors in cancer cells. In healthy cells, promoters of TSGs are unmethylated and present an enrichment of active histone marks such as acetylation and methylation (e.g., H3K4, H3K79, H3R17), which are actively maintained by HATs and HMTs, respectively. Repressive histone marks (H3K9 and H3K27) are maintained unmethylated by specific HDMs. These chromatin marks promote the recruitment of co-activator complexes such as chromatin remodeling complex (e.g., SWI/SNF), transcription factors and RNA polymerase II, which in turn trigger transcription. In cancer cells, TSGs are transcriptionally silenced due to DNMT-mediated DNA hypermethylation, which allows the recruitment of MBDs that bind methyl $\mathrm{CpG}$, which in turn promote the recruitment of repressive complexes (e.g., mSin3A or SMRT/N-CoR) and HDACs leading to histone hypoacetylation. Additionally, active histone methylation marks are removed by specific HDMs and replaced by repressive methylation marks (e.g., H3K9, H3K27, H3R2) by specific HMTs. These modifications promote chromatin condensation and block the recruitment of TF and RNA poly II complex. Consequently, inhibition of HDAC activities is responsible for the modulation of protein degradation, induction of cellular differentiation and apoptosis, and inhibition of telomerase expression and cell cycle progression. Bax Bcl-2-associated X protein, $B c l-2$ B-cell lymphoma 2, $C D K$ cyclindependent kinase, $C D K N$ CDK inhibitor, DNMT DNA methyl transferase, HAT histone acetyl transferase, HDAC histone deacetylase, $H D A C i$ HDAC inhibitor, HIF hypoxia-inducible factor, $H D M$ histone demethylase, HMT histone methyl transferase, hTERT human telomerase reverse transcriptase, $M B D$ methyl binding domain protein, Pol II RNA polymerase II, RUNX runt-related transcription factor, $\operatorname{Sin} 3$ switch intensive $3, \operatorname{Smad} 7$ mothers against decapentaplegic homolog 7, SMRT/N-CoR silencing mediator of retinoic acid and thyroid hormone receptors/nuclear hormone receptor co-repressor, SWI/SNF switch/sucrose non-Fermentable, $T F$ transcription factor, $T S G$ tumor suppressor gene 


\section{Classification of HDAC inhibitors}

Epigenetic mechanisms, in contrast to mutations, are potentially reversible and are thus, interesting therapeutic targets. With regard to the involvement of HDACs in cancer, HDAC inhibitors (HDACi) are currently under development for anticancer therapy. Most of these molecules have a binding site for catalytic zinc, a tail (linker) mimicking the side chain of lysine and a "cap" for obstructing the entrance to the active site. These inhibitors can be classified according to their structure into five categories: short-chain fatty acids, hydroxamates, cyclic peptides, benzamides and depsipeptide (Bieliauskas and Pflum 2008; Khan et al. 2008). Nevertheless, many molecules with a potential inhibitory activity against HDAC but with a chemical structure different than the first five have been identified. A significant number of these molecules were isolated from natural sources (Table 2). Among these molecules, pan-HDAC inhibitors and isoform- or classspecific inhibitors have been identified. Interestingly, HDAC inhibitors are used in anti-cancer therapy for their anti-proliferative, pro-apoptotic and anti-inflammatory activities. Moreover, HDACi can restore differentiation processes in cancer cells (Fig. 2).

\section{HDAC inhibitors of natural and dietary origins}

Within the chemical class of short-chain fatty acids, sodium butyrate is present in the gastrointestinal tract as a consequence of microbial fermentation of dietary fiber (Fig. 3). It has been shown that butyrate inhibits HDAC classes I, IIa and IV (Davie 2003). This compound leads to growth arrest, differentiation of leukemic cells and induces apoptosis following the deterioration of the anti-apoptotic protein Bcl-2 (Rosato et al. 2003; Schnekenburger et al. 2006). In addition, another short-chain fatty acid, propionate, was shown to inhibit HDAC activity (Davie 2003). Both compounds induce autophagy with the up-regulation of LAM-2 (lysosomal-associated membrane protein 2) expression and LC3 conversion (Tang et al. 2011). However, considering the low stability of this compound, its use is limited to in vitro studies.

The hydroxamic acid trichostatin A (TSA) from the actinomycete Streptomyces hygroscopicus is a potent pan-HDACi. This molecule presents anti-proliferative properties, induces apoptosis through induction of both the pro-apoptotic protein Bax and caspase 3 and reduces telomerase activity by inhibiting hTERT (human telomerase reverse transcriptase) mRNA expression (Woo et al. 2007). Suberoyanilide hydroxamic acid (SAHA) is a synthetic derivative of TSA, which was approved by FDA (Food and Drug Administration) for the treatment of cutaneous T-cell lymphoma in 2006 (Wagner et al. 2010). Interestingly, cells treated by these two related molecules enter in autophagy to protect themself from the stress induced by these drugs (Shao et al. 2004; Zou et al. 2011). Moreover, regarding the involvement of HDAC6 in the formation of aggresomes, tubacin, a synthetic hydroxamic acid that inhibits specifically HDAC6, should be able to impair autophagy (Hideshima et al. 2005). Indeed, Lee et al. 2010 shown that knock-down of HDAC6 induces a defect of fusion of autophagosomes and lysosomes resulting in an accumulation of ubiquitinated proteins.

Natural cyclic peptides have also been demonstrated to act as HDACi. This is the case of FR235222, isolated from Acremonium sp., which induces an accumulation of cells in G1 phase accompanied by an increase in p21 expression and down-regulation of cyclin $\mathrm{E}$ in the human promyelocytic leukemia U937 cell line (Petrella et al. 2008).

The depsipeptide FK228 (or Romidepsin), isolated from Chromobacterium violaceum, which preferably inhibits class I HDACs, leads to cell growth inhibition and apoptosis induction in leukemic cells (Furumai et al. 2002; Rosato et al. 2003). Moreover, this compound leads to induction of the autophagy pathway with the involvement of AIF (apoptosis inducible factor) translocation from mitochondria to the nucleus (Watanabe et al. 2009). The FDA approved this compound in 2009 for the treatment of cutaneous T-cell lymphoma (Wagner et al. 2010).

Benzamides represent a chemical class wherein no promising natural compounds have yet been identified. However, some synthetic products belong to this class, such as MS-275 and MGCD0103. Such compounds are interesting due to their selectivity against class I HDACs compared to the pan-HDACi SAHA. These molecules are currently undergoing phase II clinical trials (Khan et al. 2008).

Other chemical classes that demonstrate interesting anticancer properties have also been investigated. Psammaplin A, isolated from the marine sponge Aplysinella rhax, demonstrates inhibitory activities against class I HDACs, accompanied by an increase in histone H3 acetylation (Kim et al. 2007).

Organosulfur compounds isolated from garlic, such as allyl mercaptan (AM) and diallyl disulfide (DADS), represent an interesting class of HDACi. Indeed, AM and DADS induce, following inhibition of HDACs (including HDAC8), an increase in the acetylation of core histones $\mathrm{H} 3$ and $\mathrm{H} 4$ in the promoter region of the CDKN1A (CDK inhibitor 1A) gene. Increased CDKN1A promoter acetylation induces p21 overexpression, which subsequently leads to cell cycle arrest and apoptosis in cancer cells (Druesne et al. 2004; Link et al. 2010; Nian et al. 2008).

Isothiocyanates such as phenethyl isothiocyanate (PEITC) from cruciferous vegetables (e.g., broccoli) show inhibitory activities against HDACs and induce an increase 
Table 2 List of natural HDAC modulators

\begin{tabular}{|c|c|c|c|c|c|}
\hline Chemical class & Compound & Origin & Target & Comments & References \\
\hline \multirow[t]{5}{*}{ Cyclic peptides $^{\mathrm{a}}$} & Apicidin D & Fusarium spp. & Class I & & Han et al. (2000) \\
\hline & Azumamide E & Mycale izuensis & Class I & & Maulucci et al. (2007) \\
\hline & Chlamydocin & $\begin{array}{l}\text { Diheterospora } \\
\text { chlamydosporia }\end{array}$ & Class I & & De Schepper et al. (2003) \\
\hline & FR235222 & Acremonium sp. & Class I & & Petrella et al. (2008) \\
\hline & Trapoxin A and B & Corollospora intermedia & Class I & & Furumai et al. (2001) \\
\hline \multirow[t]{3}{*}{ Depsipepides $^{\mathrm{a}}$} & FK228 (Romidepsin) & $\begin{array}{l}\text { Chromobacterium } \\
\text { violaceum }\end{array}$ & Class I & $\begin{array}{l}\text { Approved by the FDA } \\
\text { for CTCL }\end{array}$ & Furumai et al. (2002) \\
\hline & Largazole & Symploca sp. & Class I & & Ying et al. (2008) \\
\hline & Spiruchostatin A & Pseudomonas & Class I & & Crabb et al. (2008) \\
\hline \multirow[t]{8}{*}{ Flavonoïdes } & Butein $^{\#}$ & Rhus verniciflua & SIRT1 & & Yang et al. (2009) \\
\hline & Daidzein $^{\#}$ & Soybean & SIRT1 & Clinical phase IV & $\begin{array}{l}\text { Rasbach and } \\
\text { Schnellmann (2008) }\end{array}$ \\
\hline & Flavone & Feijoa sellowiana & HDAC1 & Clinical phase II & Bontempo et al. (2007) \\
\hline & Genistein & Soy & & Clinical phase IV & Basak et al. (2008) \\
\hline & Luteolin ${ }^{\#}$ & $\begin{array}{l}\text { Sweet pepper, celery, } \\
\text { parsley }\end{array}$ & SIRT1 & & Attoub et al. (2011) \\
\hline & Pomiferin & Maclura pomifera & Class I & & Son et al. (2007) \\
\hline & Quercetin $^{\#}$ & Citrus fruits, buckwheat & SIRT1 & Clinical phase IV & Link et al. (2010) \\
\hline & Silibilin $^{\#}$ & Milk thistle & SIRT1 & & Zhou et al. (2006) \\
\hline \multirow[t]{2}{*}{ Hydroxamates $^{\mathrm{a}}$} & Amamistatin & Nocardia asteroides & & & $\begin{array}{l}\text { Fennell and Miller } \\
\text { (2007) }\end{array}$ \\
\hline & TSA & Streptomyces hygroscopius & $\begin{array}{l}\text { Class I, II and } \\
\text { IV }\end{array}$ & Too toxic & Woo et al. (2007) \\
\hline \multirow[t]{2}{*}{ Isothiocyanates } & PEITC & Cruciferous vegetables & Class I & Clinical phase II & Wang et al. (2008) \\
\hline & Sulforaphane & Cruciferous vegetables & & Clinical phase II & Myzak et al. (2004) \\
\hline \multirow[t]{3}{*}{ Organosulfures } & $\mathrm{AM}$ & Garlic (Allium sativum) & HDAC8 & & Nian et al. (2008) \\
\hline & $\begin{array}{l}\text { bis (4-hydroxybenzyl) } \\
\text { sulfide }\end{array}$ & $\begin{array}{l}\text { Knotweed (Pleuropterus } \\
\text { ciliinervis) }\end{array}$ & Class I & & Son et al. (2007) \\
\hline & DADS & Garlic (Allium sativum) & & & Druesne et al. (2004) \\
\hline \multirow[t]{2}{*}{$\begin{array}{l}\text { Short-chain fatty } \\
\text { acids }^{\mathrm{a}}\end{array}$} & Sodium butyrate & $\begin{array}{l}\text { Fermentation of dietary } \\
\text { fibers }\end{array}$ & $\begin{array}{l}\text { Class I, IIa } \\
\text { and IV }\end{array}$ & Low stability & Davie (2003) \\
\hline & Sodium propionate & $\begin{array}{l}\text { Fermentation of dietary } \\
\text { fibers }\end{array}$ & ND & & Aoyama et al. (2010) \\
\hline \multirow[t]{2}{*}{ Stilbenes } & Piceatannol $^{\#}$ & Blueberries & SIRT1 & Clinical phase IV & Wang et al. (2008) \\
\hline & Resveratrol $^{\#}$ & Red grapes & SIRT1 & & \\
\hline \multirow[t]{8}{*}{ Others } & Caffeine & Coffea arabica & HDAC5 & Clinical phase IV & Mukwevho et al. (2008) \\
\hline & Cyclostelletamines & Marine sponges & Class I & & Oku et al. (2004) \\
\hline & Dihydrocoumarin & Melilotous officinalis & SIRT1 and 2 & & Olaharski et al. (2005) \\
\hline & DIM & Cauliflower and broccoli & Class I & Clinical phase II & Bhatnagar et al. (2009) \\
\hline & Depudecin & Alternaria brassicicola & & & Kwon et al. (1998) \\
\hline & MCP30 & Bitter melon seeds & Class I & & Xiong et al. (2009) \\
\hline & Nicotinamide & Vitamin B3 metabolite & SIRT1 & Clinical phase IV & Zhang et al. (2011) \\
\hline & Psammaplin A & Aplysinella rhax & Class I & & Kim et al. (2007) \\
\hline
\end{tabular}

$A M$ allyl mercaptan, $D A D S$ diallyl disulfide, $C T C L$ cutaneous T-cell lymphoma, DIM 3,3'-diindolylmethane, FDA food and drug administration, HDAC histone deacetylase, ND not determined, PEITC phenethyl isothiocyanate, SIRT sirtuin, TSA trichostatin A

"Chemical class of compounds that have a "classical" structure of HDAC inhibitors. All molecules are HDAC inhibitors (unless otherwise indicated, " for activators). More information about clinical trials can be found at http://clinicaltrials.gov/ 
<smiles>CCCC(=O)O[Na]</smiles>

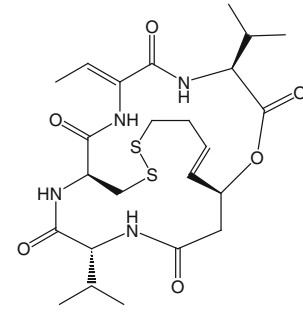

FK-228<smiles>O=c1c(-c2ccccc2)coc2ccccc12</smiles>

Isoflavone backbone<smiles>O=C1CCc2ccccc2O1</smiles>

Dihydrocoumarin<smiles>O=C(CCCCCCC(=O)Nc1ccccc1)NO</smiles>

Suberoylanilide hydroxamic acid (SAHA)

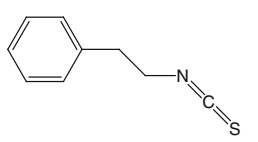

Phenyl isothiocyanate (PEITC)

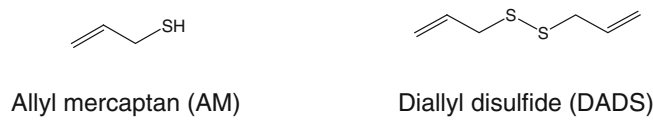<smiles>Oc1ccc(/C=C/c2cc(O)cc(O)c2)cc1</smiles>

Resveratrol

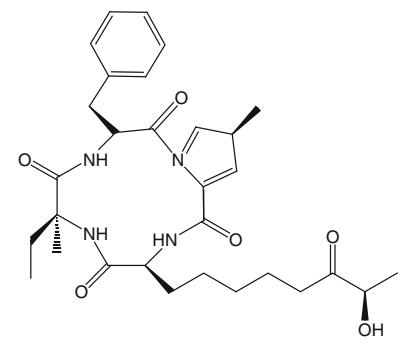

FR235222

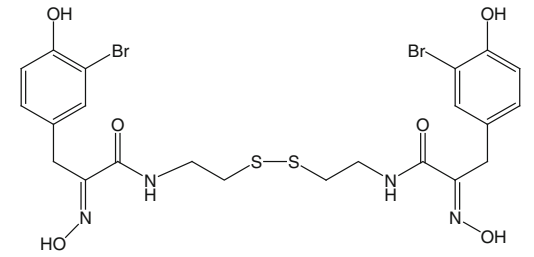

Psammaplin A<smiles>O=c1c(O)c(-c2ccc(O)c(O)c2)oc2cc(O)cc(O)c12</smiles>

Quercetin

Fig. 3 Structure of HDAC modulators

in histone acetylation, particularly at promoters of genes encoding p21 and Bax, which are involved in the cell cycle and apoptosis, respectively (Wang et al. 2008).

Indole-3-carbinol from broccoli and cauliflower is metabolized to $3,3^{\prime}$-diindolylmethane (DIM) and induces the proteasomal degradation of class I HDACs $(1,2,3$ and 8 ), thereby inhibiting the anti-apoptotic protein survivin. Moreover, it has been reported that this treatment induces the expression of the genes encoding p21 and p27, which are proteins involved in cell cycle arrest in G1 phase (Bhatnagar et al. 2009; Link et al. 2010).

Regarding class III HDACs, it seems therapeutically interesting to find activators of sirtuins. The activators resveratrol and quercetin are polyphenols isolated from grapes and citrus fruits, respectively. These molecules induce SIRT1 activity, which in turn deacetylates survivin and subsequently triggers apoptosis (Wang et al. 2008). However, it has been reported that inhibition of class III HDACs might favor tumor suppression. For example, isoflavones isolated from soybeans are capable of inhibiting HDACs and activate HATs. These modulations result in TSG activation (CDKN1A, CDKN2A and PTEN) and oncogene inhibition (hTERT; Link et al. 2010). Finally, dihydrocoumarin, a molecule isolated from Melitous officinalis that is widely used as a dietary supplement, is able to reverse heterochromatin-induced epigenetic silencing concomitantly with induction of a senescence- and aginglike phenotype associated with inhibition of SIRT1 activity, leading to an increase in p53 acetylation and apoptosis rate (Olaharski et al. 2005).

\section{Conclusion and perspectives}

Alterations in the balance of HAT/HDAC activities resulting in aberrant protein acetylation status are frequently observed in many forms of cancer. In particular, increased deacetylation is involved in epigenetically mediated TSG silencing associated with tumorigenesis. Therefore, HDACs represent a promising class of anticancer drug targets. Regarding HDACi, there are numerous molecules currently undergoing clinical trials, and some 
are already approved for anticancer therapy. HDACi have multiple biological effects (Fig. 2) that could probably be attributed to the large number of proteins post-transcriptionally modified by lysine acetylation. Consequently, it would be more appropriate to call HATs and HDACs lysine acetyltransferases (KATs) and lysine deacetyltransferases (KDACs), respectively. Furthermore, HDACi, from a chemosensitization point of view, seem particularly attractive when combined with either conventional chemotherapeutic drugs inducing apoptosis (e.g., doxorubicin or etoposide) and/or with other epigenetically active drugs, such as the DNA demethylating agent 5-aza2 -deoxycytidine, to restore epigenetically mediated gene silencing (Chai et al. 2008; Schnekenburger et al. 2011; Yoon et al. 2010). Hence, it seems that HDACi offer promising alternatives for anticancer therapies. However, researchers are still actively looking for new HDACi from natural origins because they represent an almost inexhaustible source of new chemical structures that could be used for the design of future potent HDACi and the development of new class- or isoform-specific HDACi. Among natural HDACi, dietary compounds are of particular interest because of their potential for chemoprevention purposes. Nevertheless, to fully exploit this aspect, rigorous studies still need to be conducted in order to evaluate the potential as well as the proportion of specific dietary HDACi, compared to other dietary constituents, to reduce the occurrence of cancer. In addition, it is necessary to take in account the possible side effects of a diet enriched with naturally occurring epigenetic modulators. Nonetheless, besides technical challenges, the potential of dietary HDACi and, by extension, epigenetic modulators should be considered for future cancer chemoprevention.

Acknowledgments CS and MS are supported by an Action Lions "Vaincre le Cancer" grant. M. Diederich's research at the Laboratoire de Biologie Moléculaire et Cellulaire du Cancer (LBMCC) is financially supported by the "Recherche Cancer et Sang" foundation, "Recherches Scientifiques Luxembourg," the "Een Häerz fir Kriibskrank Kanner" association, the Action Lions "Vaincre le Cancer" Luxembourg and Televie Luxembourg. Editing and print costs were covered by the Fonds National de la Recherche (FNR), Luxembourg.

\section{References}

Ahn BH, Kim HS, Song S, Lee IH, Liu J, Vassilopoulos A, Deng CX, Finkel T (2008) A role for the mitochondrial deacetylase Sirt3 in regulating energy homeostasis. Proc Natl Acad Sci USA 105:14447-14452

Aldana-Masangkay GI, Sakamoto KM (2011) The role of HDAC6 in cancer. J Biomed Biotechnol 2011:875824

Aoyama M, Kotani J, Usami M (2010) Butyrate and propionate induced activated or non-activated neutrophil apoptosis via HDAC inhibitor activity but without activating GPR-41/GPR-43 pathways. Nutrition 26:653-661
Argmann C, Auwerx J (2006) Insulin secretion: SIRT4 gets in on the act. Cell 126:837-839

Attoub S, Hassan AH, Vanhoecke B, Iratni R, Takahashi T, Gaben AM, Bracke M, Awad S, John A, Kamalboor HA, Al Sultan MA, Arafat K, Gespach C, Petroianu G (2011) Inhibition of cell survival, invasion, tumor growth and histone deacetylase activity by the dietary flavonoid luteolin in human epithelioid cancer cells. Eur J Pharmacol 651:18-25

Bali P, Pranpat M, Bradner J, Balasis M, Fiskus W, Guo F, Rocha K, Kumaraswamy S, Boyapalle S, Atadja P, Seto E, Bhalla K (2005) Inhibition of histone deacetylase 6 acetylates and disrupts the chaperone function of heat shock protein 90: a novel basis for antileukemia activity of histone deacetylase inhibitors. J Biol Chem 280:26729-26734

Basak S, Pookot D, Noonan EJ, Dahiya R (2008) Genistein downregulates androgen receptor by modulating HDAC6-Hsp90 chaperone function. Mol Cancer Ther 7:3195-3202

Bhatnagar N, Li X, Chen Y, Zhou X, Garrett SH, Guo B (2009) 3,3'diindolylmethane enhances the efficacy of butyrate in colon cancer prevention through down-regulation of survivin. Cancer Prev Res 2:581-589

Bieliauskas AV, Pflum MK (2008) Isoform-selective histone deacetylase inhibitors. Chem Soc Rev 37:1402-1413

Bontempo P, Mita L, Miceli M, Doto A, Nebbioso A, De Bellis F, Conte M, Minichiello A, Manzo F, Carafa V, Basile A, Rigano D, Sorbo S, Castaldo Cobianchi R, Schiavone EM, Ferrara F, De Simone M, Vietri M, Cioffi M, Sica V, Bresciani F, de Lera AR, Altucci L, Molinari AM (2007) Feijoa sellowiana derived natural Flavone exerts anti-cancer action displaying HDAC inhibitory activities. Int J Biochem Cell Biol 39:1902-1914

Bradbury CA, Khanim FL, Hayden R, Bunce CM, White DA, Drayson MT, Craddock C, Turner BM (2005) Histone deacetylases in acute myeloid leukaemia show a distinctive pattern of expression that changes selectively in response to deacetylase inhibitors. Leukemia 19:1751-1759

Bug G, Ottmann OG (2010) The DAC system and associations with acute leukemias and myelodysplastic syndromes. Invest New Drugs 28(Suppl 1):S36-S49

Chai G, Li L, Zhou W, Wu L, Zhao Y, Wang D, Lu S, Yu Y, Wang H, McNutt MA, Hu YG, Chen Y, Yang Y, Wu X, Otterson GA, Zhu WG (2008) HDAC inhibitors act with 5-aza-2'-deoxycytidine to inhibit cell proliferation by suppressing removal of incorporated abases in lung cancer cells. PloS One 3:e2445

Crabb SJ, Howell M, Rogers H, Ishfaq M, Yurek-George A, Carey K, Pickering BM, East P, Mitter R, Maeda S, Johnson PW, Townsend P, Shin-ya K, Yoshida M, Ganesan A, Packham G (2008) Characterisation of the in vitro activity of the depsipeptide histone deacetylase inhibitor spiruchostatin A. Biochem Pharmacol 76:463-475

Davie JR (2003) Inhibition of histone deacetylase activity by butyrate. J Nutr 133:2485S-2493S

De Schepper S, Bruwiere H, Verhulst T, Steller U, Andries L, Wouters W, Janicot M, Arts J, Van Heusden J (2003) Inhibition of histone deacetylases by chlamydocin induces apoptosis and proteasome-mediated degradation of survivin. J Pharmacology Exp Ther 304:881-888

Druesne N, Pagniez A, Mayeur C, Thomas M, Cherbuy C, Duee PH, Martel P, Chaumontet C (2004) Diallyl disulfide (DADS) increases histone acetylation and $\mathrm{p} 21$ (waf1/cip1) expression in human colon tumor cell lines. Carcinogenesis 25:12271236

Fennell KA, Miller MJ (2007) Syntheses of amamistatin fragments and determination of their HDAC and antitumor activity. Organic Lett 9:1683-1685

Finnin MS, Donigian JR, Cohen A, Richon VM, Rifkind RA, Marks PA, Breslow R, Pavletich NP (1999) Structures of a histone 
deacetylase homologue bound to the TSA and SAHA inhibitors. Nature 401:188-193

Fischle W, Dequiedt F, Hendzel MJ, Guenther MG, Lazar MA, Voelter W, Verdin E (2002) Enzymatic activity associated with class II HDACs is dependent on a multiprotein complex containing HDAC3 and SMRT/N-CoR. Molecular Cell 9:45-57

Florean C, Schnekenburger M, Grandjenette C, Dicato M, Diederich M (2011) Epigenomics of leukemia: from mechanisms to therapeutic applications. Epigenomics 3:581-609

Folmer F, Orlikova B, Schnekenburger M, Dicato M, Diederich M (2010) Naturally occurring regulators of histone acetylation/ deacetylation. Curr Nutr Food Sci 6:78-99

Furumai R, Komatsu Y, Nishino N, Khochbin S, Yoshida M, Horinouchi S (2001) Potent histone deacetylase inhibitors built from trichostatin A and cyclic tetrapeptide antibiotics including trapoxin. Proc Natl Acad Sci USA 98:87-92

Furumai R, Matsuyama A, Kobashi N, Lee KH, Nishiyama M, Nakajima H, Tanaka A, Komatsu Y, Nishino N, Yoshida M, Horinouchi S (2002) FK228 (depsipeptide) as a natural prodrug that inhibits class I histone deacetylases. Cancer Res 62:49164921

Gao L, Cueto MA, Asselbergs F, Atadja P (2002) Cloning and functional characterization of HDAC11, a novel member of the human histone deacetylase family. J Biol Chem 277:2574825755

Hallows WC, Lee S, Denu JM (2006) Sirtuins deacetylate and activate mammalian acetyl-CoA synthetases. Proc Natl Acad Sci USA 103:10230-10235

Han JW, Ahn SH, Park SH, Wang SY, Bae GU, Seo DW, Kwon HK, Hong S, Lee HY, Lee YW, Lee HW (2000) Apicidin, a histone deacetylase inhibitor, inhibits proliferation of tumor cells via induction of p21WAF1/Cip1 and gelsolin. Cancer Res 60:60686074

Hassan AH, Awad S, Al-Natour Z, Othman S, Mustafa F, Rizvi TA (2007) Selective recognition of acetylated histones by bromodomains in transcriptional co-activators. Biochem J 402:125-133

Hideshima T, Bradner JE, Wong J, Chauhan D, Richardson P, Schreiber SL, Anderson KC (2005) Small-molecule inhibition of proteasome and aggresome function induces synergistic antitumor activity in multiple myeloma. Proc Natl Acad Sci USA 102:8567-8572

Hodawadekar SC, Marmorstein R (2007) Chemistry of acetyl transfer by histone modifying enzymes: structure, mechanism and implications for effector design. Oncogene 26:5528-5540

Hoff KG, Avalos JL, Sens K, Wolberger C (2006) Insights into the sirtuin mechanism from ternary complexes containing NAD+ and acetylated peptide. Structure 14:1231-1240

Hubbert C, Guardiola A, Shao R, Kawaguchi Y, Ito A, Nixon A, Yoshida M, Wang XF, Yao TP (2002) HDAC6 is a microtubuleassociated deacetylase. Nature 417:455-458

Johnston JA, Ward CL, Kopito RR (1998) Aggresomes: a cellular response to misfolded proteins. J Cell Biol 143:1883-1898

Jones PL, Veenstra GJ, Wade PA, Vermaak D, Kass SU, Landsberger N, Strouboulis J, Wolffe AP (1998) Methylated DNA and $\mathrm{MeCP} 2$ recruit histone deacetylase to repress transcription. Nat Genet 19:187-191

Khan N, Jeffers M, Kumar S, Hackett C, Boldog F, Khramtsov N, Qian X, Mills E, Berghs SC, Carey N, Finn PW, Collins LS, Tumber A, Ritchie JW, Jensen PB, Lichenstein HS, Sehested M (2008) Determination of the class and isoform selectivity of small-molecule histone deacetylase inhibitors. Biochem $\mathrm{J}$ 409:581-589

Kim DH, Shin J, Kwon HJ (2007) Psammaplin A is a natural prodrug that inhibits class I histone deacetylase. Exp Mol Med 39:47-55

Kwon HJ, Owa T, Hassig CA, Shimada J, Schreiber SL (1998) Depudecin induces morphological reversion of transformed fibroblasts via the inhibition of histone deacetylase. Proc Natl Acad Sci USA 95:3356-3361

Lee JY, Koga H, Kawaguchi Y, Tang W, Wong E, Gao YS, Pandey UB, Kaushik S, Tresse E, Lu J, Taylor JP, Cuervo AM, Yao TP (2010) HDAC6 controls autophagosome maturation essential for ubiquitin-selective quality-control autophagy. EMBO J 29:969-980

Link A, Balaguer F, Goel A (2010) Cancer chemoprevention by dietary polyphenols: promising role for epigenetics. Biochem Pharmacol 80:1771-1792

Liu T, Liu PY, Marshall GM (2009) The critical role of the class III histone deacetylase SIRT1 in cancer. Cancer Res 69:1702-1705

Maulucci N, Chini MG, Micco SD, Izzo I, Cafaro E, Russo A, Gallinari P, Paolini C, Nardi MC, Casapullo A, Riccio R, Bifulco G, Riccardis FD (2007) Molecular insights into azumamide e histone deacetylases inhibitory activity. J Am Chem Soc 129:3007-3012

Minucci S, Pelicci PG (2006) Histone deacetylase inhibitors and the promise of epigenetic (and more) treatments for cancer. Nat Rev Cancer 6:38-51

Mukwevho E, Kohn TA, Lang D, Nyatia E, Smith J, Ojuka EO (2008) Caffeine induces hyperacetylation of histones at the MEF2 site on the Glut4 promoter and increases MEF2A binding to the site via a CaMK-dependent mechanism. American journal of physiology. Endocrinol Metab 294:E582-E588

Myzak MC, Karplus PA, Chung FL, Dashwood RH (2004) A novel mechanism of chemoprotection by sulforaphane: inhibition of histone deacetylase. Cancer Res 64:5767-5774

Nakagawa T, Guarente L (2009) Urea cycle regulation by mitochondrial sirtuin, SIRT5. Aging 1:578-581

Nakagawa T, Lomb DJ, Haigis MC, Guarente L (2009) SIRT5 Deacetylates carbamoyl phosphate synthetase 1 and regulates the urea cycle. Cell 137:560-570

Nian H, Delage B, Pinto JT, Dashwood RH (2008) Allyl mercaptan, a garlic-derived organosulfur compound, inhibits histone deacetylase and enhances Sp3 binding on the P21WAF1 promoter. Carcinogenesis 29:1816-1824

Oku N, Nagai K, Shindoh N, Terada Y, van Soest RW, Matsunaga S, Fusetani N (2004) Three new cyclostellettamines, which inhibit histone deacetylase, from a marine sponge of the genus Xestospongia. Bioorgan Med Chem Lett 14:2617-2620

Olaharski AJ, Rine J, Marshall BL, Babiarz J, Zhang L, Verdin E, Smith MT (2005) The flavoring agent dihydrocoumarin reverses epigenetic silencing and inhibits sirtuin deacetylases. PLoS Genetics 1:e77

Petrella A, D'Acunto CW, Rodriquez M, Festa M, Tosco A, Bruno I, Terracciano S, Taddei M, Paloma LG, Parente L (2008) Effects of FR235222, a novel HDAC inhibitor, in proliferation and apoptosis of human leukaemia cell lines: role of annexin A1. Eur J Cancer 44:740-749

Potente M, Ghaeni L, Baldessari D, Mostoslavsky R, Rossig L, Dequiedt F, Haendeler J, Mione M, Dejana E, Alt FW, Zeiher AM, Dimmeler S (2007) SIRT1 controls endothelial angiogenic functions during vascular growth. Genes Dev 21:2644-2658

Rasbach KA, Schnellmann RG (2008) Isoflavones promote mitochondrial biogenesis. J Pharmacology Exp Ther 325:536-543

Rosato RR, Almenara JA, Grant S (2003) The histone deacetylase inhibitor MS-275 promotes differentiation or apoptosis in human leukemia cells through a process regulated by generation of reactive oxygen species and induction of p21CIP1/WAF1 1 . Cancer Res 63:3637-3645

Schnekenburger M, Morceau F, Henry E, Blasius R, Dicato M, Trentesaux C, Diederich M (2006) Transcriptional and posttranscriptional regulation of glutathione S-transferase P1 expression during butyric acid-induced differentiation of K562 cells. Leuk Res 30:561-568 
Schnekenburger M, Grandjenette C, Ghelfi J, Karius T, Foliguet B, Dicato M, Diederich M (2011) Sustained exposure to the DNA demethylating agent, 2'-deoxy-5-azacytidine, leads to apoptotic cell death in chronic myeloid leukemia by promoting differentiation, senescence, and autophagy. Biochem Pharmacol 81:364 378

Schwer B, Bunkenborg J, Verdin RO, Andersen JS, Verdin E (2006) Reversible lysine acetylation controls the activity of the mitochondrial enzyme acetyl-CoA synthetase 2. Proc Natl Acad Sci USA 103:10224-10229

Shao Y, Gao Z, Marks PA, Jiang X (2004) Apoptotic and autophagic cell death induced by histone deacetylase inhibitors. Proc Natl Acad Sci USA 101:18030-18035

Son IH, Lee SI, Yang HD, Moon HI (2007a) Bis(4-hydroxybenzyl)sulfide: a sulfur compound inhibitor of histone deacetylase isolated from root extract of Pleuropterus ciliinervis. Molecules $12: 815-820$

Son IH, Chung IM, Lee SI, Yang HD, Moon HI (2007b) Pomiferin, histone deacetylase inhibitor isolated from the fruits of Maclura pomifera. Bioorganic \& medicinal chemistry letters 17:47534755

Spange S, Wagner T, Heinzel T, Kramer OH (2009) Acetylation of non-histone proteins modulates cellular signalling at multiple levels. Int J Biochem Cell Biol 41:185-198

Tai KY, Shiah SG, Shieh YS, Kao YR, Chi CY, Huang E, Lee HS, Chang LC, Yang PC, Wu CW (2007) DNA methylation and histone modification regulate silencing of epithelial cell adhesion molecule for tumor invasion and progression. Oncogene 26:3989-3997

Tang Y, Chen Y, Jiang H, Nie D (2011) Short-chain fatty acids induced autophagy serves as an adaptive strategy for retarding mitochondria-mediated apoptotic cell death. Cell Death Differ 18:602-618

Tong JJ, Liu J, Bertos NR, Yang XJ (2002) Identification of HDAC10, a novel class II human histone deacetylase containing a leucine-rich domain. Nucleic Acids Res 30:1114-1123

Wade PA, Gegonne A, Jones PL, Ballestar E, Aubry F, Wolffe AP (1999) Mi-2 complex couples DNA methylation to chromatin remodelling and histone deacetylation. Nat Genet 23:62-66

Wagner JM, Hackanson B, Lubbert M, Jung M (2010) Histone deacetylase (HDAC) inhibitors in recent clinical trials for cancer therapy. Clinical Epigen 1:117-136

Wang LG, Liu XM, Fang Y, Dai W, Chiao FB, Puccio GM, Feng J, Liu D, Chiao JW (2008a) De-repression of the p21 promoter in prostate cancer cells by an isothiocyanate via inhibition of HDACs and c-Myc. Int J Oncol 33:375-380

Wang RH, Zheng Y, Kim HS, Xu X, Cao L, Luhasen T, Lee MH, Xiao C, Vassilopoulos A, Chen W, Gardner K, Man YG, Hung
MC, Finkel T, Deng CX (2008b) Interplay among BRCA1, SIRT1, and Survivin during BRCA1-associated tumorigenesis. Molecular Cell 32:11-20

Watanabe M, Adachi S, Matsubara H, Imai T, Yui Y, Mizushima Y, Hiraumi Y, Watanabe K, Kamitsuji Y, Toyokuni SY, Hosoi H, Sugimoto T, Toguchida J, Nakahata T (2009) Induction of autophagy in malignant rhabdoid tumor cells by the histone deacetylase inhibitor FK228 through AIF translocation. Int J Cancer 124:55-67

Woo HJ, Lee SJ, Choi BT, Park YM, Choi YH (2007) Induction of apoptosis and inhibition of telomerase activity by trichostatin A, a histone deacetylase inhibitor, in human leukemic U937 cells. Exp Mol Pathol 82:77-84

Xiong SD, Yu K, Liu XH, Yin LH, Kirschenbaum A, Yao S, Narla G, DiFeo A, Wu JB, Yuan Y, Ho SM, Lam YW, Levine AC (2009) Ribosome-inactivating proteins isolated from dietary bitter melon induce apoptosis and inhibit histone deacetylase-1 selectively in premalignant and malignant prostate cancer cells. Int J Cancer 125:774-782

Yang J, Kong X, Martins-Santos ME, Aleman G, Chaco E, Liu GE, Wu SY, Samols D, Hakimi P, Chiang CM, Hanson RW (2009) Activation of SIRT1 by resveratrol represses transcription of the gene for the cytosolic form of phosphoenolpyruvate carboxykinase (GTP) by deacetylating hepatic nuclear factor 4alpha. J Biol Chem 284:27042-27053

Ying Y, Taori K, Kim H, Hong J, Luesch H (2008) Total synthesis and molecular target of largazole, a histone deacetylase inhibitor. J Am Chem Soc 130:8455-8459

Yoon SN, Roh SA, Cho DH, Kim MB, Hyun YL, Ro S, Kim BS, Kim SY, Kim YS, Kim JC (2010) In vitro chemosensitivity of gastric adenocarcinomas to histone deacetylase inhibitors, compared to established drugs. Hepatogastroenterology 57:657-662

Zhang Y, Ng HH, Erdjument-Bromage H, Tempst P, Bird A, Reinberg D (1999) Analysis of the NuRD subunits reveals a histone deacetylase core complex and a connection with DNA methylation. Genes Dev 13:1924-1935

Zhang Y, Wang J, Chen G, Fan D, Deng M (2011) Inhibition of Sirt1 promotes neural progenitors toward motoneuron differentiation from human embryonic stem cells. Biochem Biophys Res Commun 404:610-614

Zhou B, Wu LJ, Li LH, Tashiro S, Onodera S, Uchiumi F, Ikejima T (2006) Silibinin protects against isoproterenol-induced rat cardiac myocyte injury through mitochondrial pathway after upregulation of SIRT1. J Pharmacol Sci 102:387-395

Zou CF, Jia L, Jin H, Yao M, Zhao N, Huan J, Lu Z, Bast RC Jr, Feng Y, Yu Y (2011) Re-expression of ARHI (DIRAS3) induces autophagy in breast cancer cells and enhances the inhibitory effect of paclitaxel. BMC Cancer 11:22 